\title{
Disease onset and aging in the world of circular RNAs
}

\author{
Kenneth Maiese* \\ Cellular and Molecular Signaling, Newark, New Jersey 07101, USA
}

\begin{abstract}
Circular ribonucleic acids (circRNAs) are non-coding RNAs of approximately 100 nucleotides in length with thousands of members in mammalian cells. The presence of circRNAs is believed to be even greater than that of messenger RNAs. Identification of circRNAs occurred approximately 37 years ago with the subsequent demonstration that covalent bonds are necessary for the unique circular structure of these ribonucleic acids. However, present understanding of the complex biological role of circRNAs remains limited and requires further elucidation. CircRNAs may impact aging, multiple disorders, function as biomarkers, and are able to regulate gene expression by acting as effective microRNA (miRNA) sponges. New work suggests that circRNAs are vital for the modulation of cellular senescence and programmed cell death pathways such as apoptosis. These non-coding RNAs can control cell cycle progression, cellular proliferation, and cellular survival impacting disorders linked to aging, cardiovascular disease, and atherosclerosis through pathways that involve cyclin-dependent kinase 2 (CDK2), cyclindependent kinase inhibitor 1 (p21), and mammalian forkhead transcription factors. In addition, circRNAs can oversee cellular metabolism and disorders such as diabetes mellitus through the regulation of insulin signaling as well as limit tumor progression through Wnt signaling and $\beta$-catenin pathways. Further understanding of the biology of circRNAs offers great promise for the targeting of novel strategies against a wide spectrum of disease entities.
\end{abstract}

\section{Circular RNAs, cellular senescence, and programmed cell death}

Circular ribonucleic acids (circRNAs) are non-coding RNAs of approximately 100 nucleotides in length that were initially identified as being circular in nature [1,2]. Subsequently, these non-coding RNAs were later demonstrated to have covalent bonds that maintain the circular structure. In the body, circRNAs have thousands of members present in mammalian cells. In eukaryotic cells, circRNAs can be composed of the loop portion of intronic lariats, plant viroids, intermediates of transfer RNAs (tRNAs), antisense transcripts, circRNAs from noncoding genes, and exonic RNAs [3]. Knowledge in regards to circRNAs is rapidly growing. It is now recognized that the isoform of circRNA has a greater expression than messenger RNA (mRNA) [4]. In addition, circRNAs have both cis and trans regulation. CircRNAs have been shown to regulate gene expression through the sponging of microRNAs (miRNAs) [5].

New work has highlighted the role of circRNAs in both cellular senescence and cellular survival. It has recently been demonstrated that circRNA generated from the mammalian forkhead transcription factor Foxo3 plays a role in cellular senescence and aging. Presently in the mammalian forkhead transcription factor family, more than 100 forkhead genes and 19 human subgroups that range from FOXA to FOXS exist [6-8]. In regards to mammalian FOXO proteins, this group is assigned to the $\mathrm{O}$ class of the forkhead box class transcription factors. The family consists of FOXO1, FOXO3, FOXO4, and FOXO6 [9]. FOXO proteins are expressed in all tissues of the body [10]. For FoxO3, this mammalian transcription factor may have an important role in erythroid cell growth [11], endothelial vascular cell survival $[12,13]$, hippocampal neuronal injury $[14,15]$, neuronal cortical disease $[10,16,17]$, and behavior disorders [18]. In the cardiovascular system during aging, circRNA generated from Foxo3 (circ-Foxo3) is expressed in aged patients and murine experimental models. Silencing circFoxo3 blocks senescence in mouse embryonic fibroblasts and overexpression of circ-Foxo3 results in cell senescence [19]. In relation to the mechanisms that may account for the cellular senescence, circ-Foxo3 appears to block cell cycle progression by binding to the cell cycle proteins cyclin-dependent kinase 2 (CDK2) and cyclindependent kinase inhibitor 1 (p21) to prevent cellular proliferation [20]. Additional evidence exists for the link between circRNAs and the onset of aging processes. For example, with advanced age, increased expression of circRNAs has been demonstrated in the skeletal muscles of monkeys [21].

CircRNAs also oversee cellular survival through programmed cell death involving apoptosis $[22,23]$. In vascular smooth muscle cells and macrophages, circular antisense non-coding RNA in the INK4 locus (circANRIL) can prevent exonuclease-mediated pre-ribosomal RNA processing, ribosome biogenesis, and proliferation of cells that may lead to atherosclerosis through the induction of apoptosis [24]. It is conceivable that circANRIL could be protective against progressive cardiovascular disease. CircRNA also can function as an endogenous miR-223 sponge to inhibit cardiac hypertrophy and heart failure [25]. However, circRNAs may not always be protective against apoptotic pathways. During cell models of ischemia-reperfusion injury, upregulation of specific circRNAs may foster apoptotic cell injury [26]. In experimental models of myocardial infarction, the circRNA Cdrlas could increase cardiac infarct size and function as a sponge for miR-7a, a protective agent in this model [27].

*Correspondence to: Kenneth Maiese, MD, Cellular and Molecular Signaling, USA, E-mail: wntin75@yahoo.com

Key words: aging, apoptosis, autophagy, $\beta$-catenin, biomarkers, cancer cardiovascular disease, cyclin-dependent kinase 2 (CDK2), cyclin-dependent kinase inhibitor 1 (p21), cell cycle, circular RNA, diabetes mellitus, endothelial cells, forkhead transcription factors, FoxO, metabolism, microRNA, p21, programmed cell death, reactive oxygen species, senescence, stem cells, transcription factors, vascular smooth muscle cells, Wht signaling

Received: August 12, 2016; Accepted: August 29, 2016; Published: August 31 , 2016 


\section{Circular RNAs, metabolism, and cellular proliferation}

Given the role of circRNAs in senescence, aging, and cell death, it is of interest to learn that circRNAs may control these processes through proliferative pathways that involve cellular metabolism and Wnt signaling [28]. During cellular metabolism, circRNAs may have a significant role in the development of diabetes mellitus (DM) [29]. DM affects the global population and is increasing in incidence throughout the world [30,31]. Approximately 350 million individuals currently have DM and an additional 8 million individuals are believed to be undiagnosed at present $[30,32]$. CircRNA Cdr1as may regulate insulin secretion through miR-7. Cdrlas is a sponge and inhibitor of miR7. Without modulation of miR-7 expression, miR-7 can foster the progression of DM. Cdrlas appears to interact with miR-7, block its activity, and increase insulin content and secretion in islet cells [33].

CircRNAs also can control cellular growth through Wnt signaling pathways and function as biomarkers for disease progression and treatment Wnt proteins are cysteine-rich glycosylated proteins that oversee multiple cellular processes including neuronal development $[34,35]$, musculoskeletal development [36,37], vascular growth [38], immunity [39], fibrosis [40,41], and stem cell proliferation [30,42,43]. However, Wnt signaling pathways also can lead to tumorigenesis since Wnt proteins are proliferative in nature [34,44-47]. CircRNAs have been reported to have a protective effect during colorectal cancer. cir-ITCH expression was found to be down-regulated in colorectal cancer when compared to normal surrounding tissue. Yet, cir-ITCH was found to be able to increase the level of ITCH that can inhibit the $\mathrm{Wnt} / \beta$-catenin pathway and block colorectal tumor progression [48]. In regards to biomarker disease assessment, circRNAs may offer the ability to track disease progression such as during hepatocellular carcinoma [49]. Yet, oncology is not the only discipline that circRNAs may function as relevant biomarkers. For example, in patients with psychiatric disease, circRNAs may be both a diagnostic and therapeutic biomarker for major depressive disorder [50].

\section{Future considerations}

As non-coding RNAs, circRNAs are ubiquitous, have thousands of members, and can regulate gene expression by functioning as effective miRNA sponges. Since circRNAs are present in exosomes, these non-coding RNAs have the ability to impact multiple cellular responses throughout the body. Under several conditions, circRNAs may control disease progression and are considered important biomarkers for multiple disorders. CircRNAs appear to be critical for the control of cellular senescence and cellular death pathways such as apoptosis. CircRNAs interface with multiple pathways that include cyclin-dependent kinase 2 (CDK2), cyclin-dependent kinase inhibitor 1 (p21), mammalian forkhead transcription factors, insulin signaling, Wnt, and $\beta$-catenin pathways. Ultimately, circRNAs may have control over aging dependent pathways, cell survival during acute injury, metabolic homeostasis, and tumorigenesis. Given that the identity of circRNAs occurred approximately 37 years ago [2], we currently have only a small grasp of the role that circRNAs play in disease onset and aging. Further efforts are clearly warranted to fully elucidate the biology of these unique non-coding RNAs in the body.

\section{Acknowledgments}

This research was supported by the following grants to Kenneth Maiese: American Diabetes Association, American Heart Association, NIH NIEHS, NIH NIA, NIH NINDS, and NIH ARRA.

\section{Competing interests}

There are no conflicts of interest to declare.

\section{References}

1. Cocquerelle C, Mascrez B, Hétuin D, Bailleul B (1993) Mis-splicing yields circular RNA molecules. FASEB J 7: 155-160. [Crossref]

2. Hsu MT, Coca-Prados M (1979) Electron microscopic evidence for the circular form of RNA in the cytoplasm of eukaryotic cells. Nature 280: 339-340. [Crossref]

3. Chen L, Huang C, Wang X, Shan G (2015) Circular RNAs in Eukaryotic Cells. Curr Genomics 16: 312-318. [Crossref]

4. Salzman J, Chen RE, Olsen MN, Wang PL, Brown PO (2013) Cell-type specific features of circular RNA expression. PLoS Genet 9: e1003777. [Crossref]

5. Zheng Q, Bao C1, Guo W1,2, et al. (2016) Circular RNA profiling reveals an abundant circHIPK 3 that regulates cell growth by sponging multiple miRNAs. Nat Commun 7: 11215. [Crossref]

6. Maiese K (2015) FoxO proteins in the nervous system. Anal Cell Pathol (Amst) 2015: 569392. [Crossref]

7. Maiese K, Chong ZZ, Shang YC (2008) OutFOXOing disease and disability: the therapeutic potential of targeting FoxO proteins. Trends Mol Med 5: 219-27. [Crossref]

8. Weigel D, Jürgens G, Küttner F, Seifert E, Jäckle H (1989) The homeotic gene fork head encodes a nuclear protein and is expressed in the terminal regions of the Drosophila embryo. Cell 57: 645-658. [Crossref]

9. Maiese K (2015) FoxO Transcription Factors and Regenerative Pathways in Diabetes Mellitus. Curr Neurovasc Res 12: 404-413. [Crossref]

10. Maiese K (2016) Forkhead transcription factors: new considerations for alzheimer's disease and dementia. J Transl Sci 2: 241-247. [Crossref]

11. Chamorro ME, Wenker SD, Vota DM, Vittori DC, Nesse AB (2013) Signaling pathways of cell proliferation are involved in the differential effect of erythropoietin and its carbamylated derivative. Biochim Biophys Acta 1833: 1960-1968. [Crossref]

12. Hou J, Wang S, Shang YC, Chong ZZ, Maiese K (2011) Erythropoietin Employs Cell Longevity Pathways of SIRT1 to Foster Endothelial Vascular Integrity During Oxidant Stress. Curr Neurovasc Res 8: 220-235. [Crossref]

13. Maiese K, Chong ZZ, Shang YC, Hou J (2009) A "FOXO" in sight: targeting Foxo proteins from conception to cancer. Med Res Rev 29: 395-418. [Crossref]

14. Park SH, Sim YB, Lee JK, Lee JY, et al. (2016) Characterization of temporal expressions of FOXO and pFOXO proteins in the hippocampus by kainic acid in mice: involvement of NMDA and non-NMDA receptors. Arch Pharm Res 39: 660-667. [Crossref]

15. Wang S, Chong ZZ, Shang YC, Maiese K (2013) WISP1 neuroprotection requires FoxO3a post-translational modulation with autoregulatory control of SIRT1. Curr Neurovasc Res 10: 54-69. [Crossref]

16. Fernandez AM, Hervas R, Dominguez-Fraile M, et al. (2016) Blockade of the Interaction of Calcineurin with FOXO in Astrocytes Protects Against Amyloid- $\hat{\mathrm{I}}^{2}$ Induced Neuronal Death. J Alzheimers Dis 52: 1471-1478. [Crossref]

17. Shi C, Zhu J, Leng S, Long D, Luo X (2016) Mitochondrial FOXO3a is involved in amyloid $\hat{\mathrm{I}}^{2}$ peptide-induced mitochondrial dysfunction. J Bioenerg Biomembr 48: 189196. [Crossref]

18. Zeng Z, Wang X, Bhardwaj SK, Zhou X, Little PJ, et al. (2016) The Atypical Antipsychotic Agent, Clozapine, Protects Against Corticosterone-Induced Death of PC12 Cells by Regulating the Akt/FoxO3a Signaling Pathway. Mol Neurobiol. [Crossref]

19. Du WW, Yang W, Chen Y, Wu ZK, Foster FS, et al. (2016) Foxo3 circular RNA promotes cardiac senescence by modulating multiple factors associated with stress and senescence responses. Eur Heart J. [Crossref]

20. Du WW, Yang W, Liu E, Yang Z, Dhaliwal P, et al. (2016) Foxo3 circular RNA retards cell cycle progression via forming ternary complexes with p21 and CDK2. Nucleic Acids Res 44: 2846-2858. [Crossref]

21. Abdelmohsen K, Panda AC, De S, Grammatikakis I, Kim J, et al. (2015) Circular RNAs in monkey muscle: age-dependent changes. Aging (Albany NY) 7: 903-910. [Crossref]

22. Klionsky DJ, Abdelmohsen K, Abe A, Abedin MJ, Abeliovich H, et al. (2016) Guidelines for the use and interpretation of assays for monitoring autophagy (3rd edition). Autophagy 12: 1-222.[Crossref] 
23. Maiese K, Chong ZZ, Shang YC, Wang S (2012) Targeting disease through novel pathways of apoptosis and autophagy. Expert Opin Ther Targets 16: 1203-1214. [Crossref]

24. Holdt LM, Stahringer A, Sass K, Pichler G, et al. (2016) Circular non-coding RNA ANRIL modulates ribosomal RNA maturation and atherosclerosis in humans. Nat Commun 7: 12429. [Crossref]

25. Wang K, Long B, Liu F, Wang JX, Liu CY, et al. (2016) A circular RNA protects the heart from pathological hypertrophy and heart failure by targeting miR-223. Eur Heart $J$. [Crossref]

26. Lin SP, Ye S, Long Y, Fan Y, Mao HF, et al. (2016) Circular RNA expression alterations are involved in OGD/R-induced neuron injury. Biochem Biophys Res Commun 471: 52-56. [Crossref]

27. Geng HH, Li R, Su YM, Xiao J, Pan M, et al. (2016) The Circular RNA Cdrlas Promotes Myocardial Infarction by Mediating the Regulation of miR-7a on Its Target Genes Expression. PLoS One 11: e0151753. [Crossref]

28. Maiese K (2015) Novel applications of trophic factors, Wnt and WISP for neuronal repair and regeneration in metabolic disease. Neural Regen Res 10: 518-528. [Crossref]

29. Maiese K (2015) New Insights for Oxidative Stress and Diabetes Mellitus. Oxid Med Cell Longev 2015: 875961. [Crossref]

30. Maiese K (2016) Novel nervous and multi-system regenerative therapeutic strategies for diabetes mellitus with mTOR. Neural regeneration research 11:372-385. [Crossref]

31. Marrif HI, Al-Sunousi SI (2016) Pancreatic $\hat{~}^{2}$ Cell Mass Death. Front Pharmacol 7: 83. [Crossref]

32. Harris MI, Eastman RC (2000) Early detection of undiagnosed diabetes mellitus: a US perspective. Diabetes Metab Res Rev 16: 230-236. [Crossref]

33. Xu H, Guo S, Li W, Yu P (2015) The circular RNA Cdr1as, via miR-7 and its targets, regulates insulin transcription and secretion in islet cells. Sci Rep 5: 12453. [Crossref]

34. Maiese K (2014) WISP1: Clinical insights for a proliferative and restorative member of the CCN family. Curr Neurovasc Res 11: 378-389. [Crossref]

35. Maiese K, Li F, Chong ZZ, Shang YC (2008) The Wnt signaling pathway: aging gracefully as a protectionist? Pharmacol Ther 118: 58-81. [Crossref]

36. Lu S1, Liu H, Lu L, Wan H, Lin Z, et al. (2016) WISP1 overexpression promotes proliferation and migration of human vascular smooth muscle cells via AKT signaling pathway. Eur J Pharmacol 788: 90-97. [Crossref]

37. Maiese K (2016) Picking a bone with WISP1 (CCN4): new strategies against degenerative joint disease. J Transl Sci 1: 83-85. [Crossref]
38. Cheng CW, Smith SK, Charnock-Jones DS (2003) Wnt-1 signaling inhibits human umbilical vein endothelial cell proliferation and alters cell morphology. Exp Cell Res 291: 415-425. [Crossref]

39. L'Episcopo F, Tirolo C, Caniglia S, Testa N, Morale MC, et al. (2014) Targeting Wnt signaling at the neuroimmune interface for dopaminergic neuroprotection/repair in Parkinson's disease. J Mol Cell Biol 6: 13-26. [Crossref]

40. Berschneider B, Ellwanger DC, Baarsma HA, Thiel C, Shimbori C, et al. (2014) miR92a regulates TGF-Î̃ 1 -induced WISP1 expression in pulmonary fibrosis. Int $J$ Biochem Cell Biol 53: 432-441. [Crossref]

41. Jian YC, Wang JJ, Dong S, Hu JW, Hu LJ, et al. (2014) Wnt-induced secreted protein 1/CCN4 in liver fibrosis both in vitro and in vivo. Clin Lab 60: 29-35. [Crossref]

42. Cernea M, Tang W, Guan H, Yang K (2016) Wisp1 mediates Bmp3-stimulated mesenchymal stem cell proliferation. J Mol Endocrinol 56: 39-46. [Crossref]

43. Shah N, Morsi Y, Manasseh R (2014) From mechanical stimulation to biological pathways in the regulation of stem cell fate. Cell Biochem Funct 32: 309-325. [Crossref]

44. Knoblich K, Wang HX, Sharma C, Fletcher AL, Turley SJ, et al. (2014) Tetraspanin TSPAN12 regulates tumor growth and metastasis and inhibits $\hat{\mathrm{I}}^{2}$-catenin degradation. Cell Mol Life Sci 71: 1305-1314. [Crossref]

45. Loilome W, Bungkanjana P, Techasen A, Namwat N, Yongvanit P, et al. (2014) Activated macrophages promote $\mathrm{Wnt} / \hat{\mathrm{I}}^{2}$-catenin signaling in cholangiocarcinoma cells. Tumour Biol 35: 5357-5367. [Crossref]

46. Mercer KE, Hennings L, Sharma N, Lai K, Cleves MA, et al. (2014) Alcoho consumption promotes diethylnitrosamine-induced hepatocarcinogenesis in male mice through activation of the Wnt/beta-catenin signaling pathway. Cancer prevention research (Philadelphia, Pa). 7: 675-685. [Crossref]

47. Yang ZH, Zheng R, Gao Y, Zhang Q, Zhang H (2014) Abnormal gene expression and gene fusion in lung adenocarcinoma with high-throughput RNA sequencing. Cancer Gene Ther 21: 74-82. [Crossref]

48. Huang G, Zhu H, Shi Y, Wu W, Cai H, et al. (2015) cir-ITCH plays an inhibitory role in colorectal cancer by regulating the $\mathrm{Wnt} / \mathrm{I}^{2}$-catenin pathway. PLoS One 10: $\mathrm{e} 0131225$. [Crossref]

49. Shang X, Li G, Liu H, Li T, Liu J, et al. (2016) Comprehensive Circular RNA Profiling Reveals That hsa circ 0005075, a New Circular RNA Biomarker, Is Involved in Hepatocellular Crcinoma Development. Medicine (Baltimore) 95: e3811. [Crossref]

50. Cui X, Niu W, Kong L, He M, Jiang K, et al. (2016) hsa circRNA_103636: potential novel diagnostic and therapeutic biomarker in Major depressive disorder. Biomark Med. [Crossref]

Copyright: (C2016 Maiese K. This is an open-access article distributed under the terms of the Creative Commons Attribution License, which permits unrestricted use, distribution, and reproduction in any medium, provided the original author and source are credited. 